CDD: 658.40388

\title{
CENTRAL DE INFORMAÇÕES EM ORGANIZAÇÕES PÚBLICAS: FERRAMENTA DE GESTÃO INFORMACIONAL
}

\section{CENTRAL OF INTELLIGENCE IN PUBLIC ORGANIZATIONS: INFORMATIONAL} MANAGEMENT TOOL

\section{Daniela do Amaral Oliveira Gardin ${ }^{1}$ Marlete Beatriz Maçaneiro ${ }^{2}$}

\begin{abstract}
Resumo: Este artigo investigou a realização da gestão informacional da Central de Informações (CEINF), de uma Universidade Pública do estado do Paraná. Para isso, foi estabelecido o objetivo geral de investigar como poderia ser melhorada a execução das suas atividades ao se apresentar como importante instrumento de gestão da massa informacional da instituição. Quanto à sua natureza, a pesquisa foi aplicada e sua abordagem foi qualitativa e descritiva, por meio de estudo de caso. Para a coleta de dados, foram utilizados os instrumentos de observação direta não-participante, realização de entrevistas e aplicação de questionários. Como principais resultados, verificou-se que os públicos interno e externo reconhecem parcialmente o potencial informativo que a CEINF tem condições de oferecer, bem como a sua eficiência como verdadeira ferramenta de gestão. Para redirecionar esse reconhecimento, foram sugeridas algumas ações com vistas à melhoria da gestão, dos atendimentos e dos serviços oferecidos pela CEINF.
\end{abstract}

Palavras-chave: Sociedade da Informação. Gestão Informacional. Central de Informações. Ferramenta de Gestão.

Abstract: This paper investigated the performance of informational management of the Central de Informações (CEINF), at a public university in the state of Paraná, Brazil. For this, the overall goal established was to investigate how its activities could be improved to present itself as an important tool of informational mass management of the institution. In nature, the research was applied and its approach was qualitative and descriptive, through case study. For data collection, it was used the instruments of non-participant direct observation, interviews and questionnaires. As main results, it was found that the internal and external audience recognizes, partially, the informative potential that CEINF is able to offer, as well as its efficiency as a true management tool. To redirect this recognition it was suggested some actions aimed at improving the management, attendances and services offered by CEINF.

Key-words: Information Society. Information Management. Information Center. Management Tool.

\footnotetext{
${ }^{1}$ Universidade Estadual do Centro-Oeste - UNICENTRO. Servidora da UNICENTRO. Bacharel em Ciências Contábeis. Mestre em Gestão da Informação pela Universidade Estadual de Londrina - UEL. Brasil. E-mail: dany.amaral@ gmail.com

${ }^{2}$ Universidade Estadual do Centro-Oeste - UNICENTRO. Professora do Departamento de Secretariado Executivo da UNICENTRO. E-mail: marlete.beatriz@yahoo.com.br
} 


\section{INTRODUÇÃO}

O sucesso organizacional na Sociedade da Informação e do Conhecimento parece ser um objetivo plenamente alcançável, mas de busca constante e de desafios complexos. No Século XXI, para se atingir as metas que proporcionem a obtenção da excelência dos processos organizacionais, são necessários diversos aspectos como, por exemplo, respostas adequadas às recentes crises sócio-político-econômicas mundiais, um quadro de funcionários com alta capacitação, uma gestão organizacional competente e adaptada às mudanças aceleradas dessa sociedade.

Nesse cenário, é imperativo que as organizações - tanto privadas como públicas - adéquem-se e agreguem aos seus instrumentos de gestão o ferramental que as inovações tecnológicas, aliadas à gestão informacional e comunicacional, podem proporcionar como ferramentas de eficiência. A gestão eficiente da informação organizacional, combinada com a gestão do conhecimento e com os avanços da era tecnológica, permite às organizações de qualquer setor de atividade a implantação de ações visando à vantagem competitiva.

A mesma configuração vale para a esfera pública, embora nela não se caracterize a busca pelo lucro financeiro, mas sim pela melhor aplicação de orçamentos pré-estabelecidos, bem como a sua manutenção com recursos oriundos de órgãos de fomento e afins. Nesse sentido, a gestão informacional de uma empresa pública possui as mesmas particularidades das não públicas, visto que a otimização e eficiência do uso daqueles recursos são necessárias nos mesmos moldes das empresas que visam lucro financeiro.

Nesse contexto, origina-se a investigação deste estudo acerca da realização da gestão informacional da Central de Informações (CEINF), de uma universidade pública estadual do Paraná ${ }^{3}$. Para essa Universidade gerir e administrar a massa informacional de toda a sua estrutura e realizar as funções-base que são, genericamente, voltadas ao ensino, à pesquisa e à extensão, conta com aproximadamente 1.384 servidores, dos quais 243 são agentes universitários (efetivos e colaboradores), 768 são professores (efetivos e colaboradores), 46 contratados em cargos comissionados, 312 estagiários e 15 funcionários da Universidade Aberta do

\footnotetext{
${ }^{3}$ Para se resguardar o sigilo da instituição pesquisada, será apenas utilizado o termo "Universidade" para se referir a ela.
} 
Brasil $(\mathrm{UAB})^{4}$. Juntos, alunos, servidores e comunidade "esporádica" (participantes de projetos de extensão, pesquisa, atividades culturais, entre outros) formam os integrantes da chamada comunidade acadêmica, os quais se movimentam diariamente nessas unidades e demandam a circulação de informações necessárias ao desenvolvimento de todas as atividades fim e meio da universidade.

Para atender a essa demanda, foi criada e implantada no ano de 2005 a CEINF, com dois objetivos: a) estudar o conteúdo próprio da informação e o seu desenvolvimento, analisando, desenhando e criando sistemas, métodos, instrumentos e técnicas de tratamento, armazenamento, recuperação e difusão da informação; e b) colocar ao alcance do público as informações disponíveis. Atualmente, a gestão da CEINF é realizada pela Chefia de Gabinete da Universidade. O atendimento no local é realizado por estagiários que executam as atividades nos três períodos letivos e administrativos da Universidade.

Dessa maneira, o objetivo geral deste artigo foi de investigar como pode ser melhorada a execução das atividades de gestão informacional dessa Central de Informações. Como objetivos específicos, este estudo pretendeu: a) realizar levantamento e descrição do número médio de atendimentos mensais realizados pela CEINF; b) conhecer o nível de satisfação dos usuários da CEINF com relação aos serviços prestados; e c) sugerir a implantação de novas ações que proporcionem a melhoria da eficiência dos serviços prestados pela CEINF.

Desse modo, a implantação de algumas ações, com vistas ao melhoramento da gestão da informação da CEINF parecem ser possíveis de se alcançar. Para confirmar esses pressupostos, autores da área da Gestão da Informação, bem como da Administração com ênfase na Gestão de Pessoas foram consultados e serão discutidos no tópico que segue.

\section{A SOCIEDADE DO CONHECIMENTO E A INFORMAÇÃO PARA AS ORGANIZAÇÕES DO SÉCULO XXI}

Há pouco mais de vinte anos, o cenário econômico mundial tem passado por transformações aceleradas, marcantes e desafiadoras, no qual a competitividade do mundo dos negócios se acirrou. Vive-se um momento em que os gestores, para

\footnotetext{
${ }^{4}$ Dados coletados junto à Diretoria de Recursos Humanos da Universidade, em julho de 2012.

\begin{tabular}{|l|l|l|l|l|l|l|}
\hline (C) Rev. digit. bibliotecon. cienc. inf. & Campinas, SP & v.11 & n.3 & p.93-119 & set./dez. 2013 & ISSN 1678-765X \\
\hline
\end{tabular}
}


administrarem bem, necessitam estar atualizados a toda e qualquer inovação que agregue conhecimento para suas organizações. Ressalta-se que conhecer o significado e a importância do ativo conhecimento é questão de sobrevivência para toda organização, considerando que se vive sob a expansão da Sociedade do Conhecimento.

Segundo Aguiar Filho (2006), a Sociedade do Conhecimento também pode ser chamada de Sociedade da Informação ou Nova Economia. O autor defende que ela surgiu no fim do Século XX e é vinda da expressão globalização, encontrando-se atualmente em processo de formação e expansão. Dessa forma, considera-se que as organizações vivem uma época de (re)aprendizado em que se tem descoberto outros novos insumos, os quais são considerados agora como essenciais à gestão. Então, sob uma nova visão, além de conhecimento, outra expressão que passou a ser integrada à sociedade é a informação, a qual Drucker (2000, p. 13) define como um "dado investido de relevância e propósito". Segundo Coelho (2006, p. 12), “A informação está intrínseca em toda a rotina da organização, é essencial à tomada de decisão e à criação de conhecimento organizacional". Choo (2003, p. 27), afirma que "a informação é um componente intrínseco de quase tudo que uma organização faz".

Portanto, a informação sendo reconhecida como recurso fundamental, como ativo de grande relevância e como agregadora de valor aos processos da organização, faz-se necessária à criação de mecanismos de identificação da informação no contexto organizacional. "Sendo assim, o seu diagnóstico é de extrema importância, na medida em que constitui etapa essencial para reconhecer se os processos de uma organização estão operando de forma eficiente.” (CORREIA, 2003, p. 29). No entanto, há um dificultador, pois, conforme defende Aguiar Filho (2006, p. 10), "não basta às organizações possuir informações de qualidade, é necessário disponibilizá-las adequadamente para o público certo, no tempo certo. Isto implica em [...] uma preocupação quanto ao gerenciamento da informação nas organizações".

Nesse sentido, os próximos tópicos deste capítulo tratarão da gestão da informação e da tecnologia da informação, aliadas à mediação humana como recursos comunicacionais.

\section{Gestão da Informação como Aspecto Vital para o Sucesso Organizacional e o} Papel do seu Gestor 
Diversos autores têm debatido acerca da Gestão da Informação (GI) nas organizações (DAVENPORT, 2000; PONJUÁN DANTE, 2004; BRETZKE, 2000; BARRETO, 2006). Observa-se nesses estudos o consenso sobre a importância e a necessidade das organizações considerarem e tratarem a gestão da informação como aspecto vital para a competitividade e o sucesso organizacional.

Dessa forma, faz-se necessário definir antes o que é gestão da informação, segundo alguns desses autores. Davenport (2000) explica que o processo de gerenciamento da informação é um ciclo integrado de atividades, envolvendo a coleta, o tratamento, o armazenamento e a distribuição da informação. Para Ponjuán Dante (2004, p. 17, tradução nossa), a gestão da informação é um processo

pelo qual se obtém, desdobram-se ou se utilizam recursos básicos (financeiros, físicos, humanos, materiais) para gerenciar informações internas e para a sociedade que serve. Tem como elemento básico a gestão do ciclo de vida deste recurso e ocorre em qualquer organização.

Assim, sustenta-se que todo e qualquer processo envolvendo a GI depende essencialmente e não ocorre sem a presença do capital humano. É indispensável, neste momento, o estabelecimento do capital humano como principal ativo dos processos organizacionais que envolvem a informação. Esse pensamento é reforçado por Molina (2008, p. 73) que assevera:

O homem é o "recurso" de maior importância no universo organizacional, pois é ele quem projeta, estrutura, implanta e usa todos os processos existentes na organização. Assim, é necessário criar um ambiente interativo, inserindo-o no processo de gestão da informação, de forma que ela ocorra da melhor forma possível.

Portanto, torna-se necessário destacar a figura do gestor de informação dentro da organização. Ele, especificamente, por meio de ferramentas disponíveis, e em conjunto com os profissionais de outras áreas, terá a função de coletar, processar e disponibilizar a informação. Mas, para realizar essas três etapas básicas e essenciais, terá de executar antes diversas ações como localizar, identificar, organizar, recuperar, 
tratar, converter e registrar a informação relevante dentro de uma imensa gama de dados.

Barreto (2006) menciona que, com a necessidade de gerir as questões da informação e do conhecimento, vê-se um maior reconhecimento sendo oferecido ao profissional da informação, que passa a ser visto como o gestor da informação. $O$ gestor da informação necessita desenvolver novas habilidades demandadas por esse novo ambiente da Sociedade da Informação. Para Aguiar Filho (2006), é necessário que as pessoas ligadas à informação cooperem entre si, fazendo com que o processo de gestão possa contribuir efetivamente para o alcance dos objetivos organizacionais.

Definido o papel da informação e de seu gestor no contexto de gerenciamento, é importante discutir sobre o ferramental necessário para a execução das atividades de gestão da informação e para a realização prática desses processos dinâmicos e otimizados. É nesse aspecto que surge a utilização das ferramentas de Tecnologia da Informação, sem deixar de considerar a mediação humana para a comunicação nas organizações. Esses aspectos serão tratados no próximo tópico deste capítulo.

\section{A Tecnologia da Informação, a Mediação Humana e a Comunicação}

A utilização de ferramentas para automação dos processos ganhou evidência com os avanços que a Tecnologia da Informação (TI) teve na Sociedade da Informação. Para Gonçalves (1993, p. 114),

\footnotetext{
dentre as várias tecnologias que tiveram impacto na realização do trabalho recentemente, a de informática é a que tem despertado maior atenção, uma vez que sua utilização é muito disseminada em diversos ambientes de trabalho e a abrangência de seus impactos é muito ampla [...].
}

Desse modo, a utilização da TI no gerenciamento da informação deve ser incentivada e priorizada. No entanto, esse uso deve ser coerente, sempre levando em consideração que essas ferramentas não são a gestão propriamente dita, mas apenas um meio de realizá-la. Essa afirmação é corroborada por Coelho (2006, p. 23), quando menciona que "[...] a questão tecnológica não configura, de forma isolada, um processo de gestão da informação e, muito menos de gestão do conhecimento". 
Na mesma linha de pensamento, Davenport, Marchand e Dickson (2004) ressaltam que somente a disponibilização e o uso da tecnologia não bastam para o adequado tratamento e disseminação da informação. Sistemas e ferramentas são desenvolvidos, mas o uso da capacidade humana em utilizar-se desse potencial ainda é e sempre será necessário para que esse ferramental seja adequadamente utilizado. Ou seja, quanto mais eficaz for a intervenção humana na identificação das necessidades informacionais e no correto ordenamento e aplicação das tecnologias de informação na gestão informacional, mais otimizados serão os resultados. Isto quer dizer que o desenvolvimento dos sistemas de informação deve obedecer a essas necessidades informacionais, as quais precisam estar em consonância com a estrutura, objetivos e funções, isto é, com a realidade organizacional vivida.

Segundo Polloni (2000, p. 54), sistema de informação é “[...] qualquer sistema que processe informações e produza resultados para um fim específico, em que cada um de seus integre um sistema automatizado de uma organização." Porém, para que a informação seja útil, deve descrever a realidade e estar disponível segundo as necessidades da administração da organização. Para Beuren (2000, p. 29), “ao se projetar um sistema de informações, faz-se necessário analisar cuidadosamente o processo de decisão e o fluxo de informações existente."

Dessa maneira, toda a gestão da vasta gama de informações que circulam nas organizações passa a integrar as suas ações estratégicas e podem ser monitoradas por meio dos Sistemas de Informação (SIs). Uma ação estratégica pode ser reconhecida, por exemplo, como uma resposta a um problema informacional que pode ser "obter a informação correta, na hora certa, na forma/meio correto e endereçá-la à pessoa certa." (ALVARENGA NETO, 2002, p. 60). Esse tipo de estratégia é conhecida como Gestão de Recursos Informacionais (GRI).

Já outra ação estratégica relacionada à gestão da informação é explicada por Molina (2008, p. 70) e "refere-se ao fato dela atuar em atividades de coleta, filtragem, tratamento e disseminação da informação, através de estruturas informáticas, que auxiliam enormemente essas tarefas”. Nesse contexto, surgem 
novos aspectos específicos, ainda não tratados neste estudo, que são as ações de compartilhamento e distribuição da informação. Realizados os procedimentos básicos com relação ao tratamento da informação, é necessária a comunicação de seu conteúdo. Surge então, nesse momento, a associação da informação com a comunicação junto aos ambientes interno e externo das organizações. Assim, seja por meio de qualquer formato, a distribuição da informação corresponde a uma etapa do processo de gerenciamento da informação.

Essa integração também é reconhecida, por exemplo, por Mendes (2005, apud BARRETO, 2006, p. 56), quando afirma que a informação é compartilhada de pessoa a pessoa, sustentada pelo convívio e pela comunicação. Dessa forma, afirma-se que todo processo informacional depende e é processado por meio dos instrumentos da comunicação e, nesse contexto, a presença humana também é necessária, pois envolve um emissor e um receptor. Maimone (2007, p. 21-22) explica que "trata-se de um processo de transferência de conteúdo, envolvendo emissor e receptor, que tem a possibilidade de modificar o estado de consciência das pessoas, embutindo a importância da informação como elemento intermediário do conhecimento.”

Considerando que a principal função da comunicação no contexto informacional é o compartilhamento e disseminação de mensagens, é importante que os profissionais dessas áreas busquem instrumentos que permitam que essas ações serem executadas com a maior qualidade e eficácia possível. Dessa forma, mais uma vez, são incluídas neste contexto as ferramentas de tecnologia de informação e comunicação, porque de fato elas contribuem sobremaneira nesses processos. As tecnologias de informação e comunicação proporcionam, por exemplo, a ampliação dos canais de distribuição de informações e facilitam o trabalho do gestor da informação tanto em nível interno como externo na organização. Internamente podem ser tomados como exemplo os canais que distribuem as informações por meio da intranet e os boletins informativos e externamente tem-se como exemplo as informações disseminadas por meio dos portais institucionais.

Todo esse conjunto, informação, comunicação e tecnologia, realizado pelo ativo humano, envolvem os principais insumos de uma organização e sua integração é indispensável em benefício da construção e consolidação do conhecimento organizacional. É uma relação de coletividade que tem características fortes da era 
globalizada em que a sociedade vive e a qual é descrita por Castells (2009). Esse autor considera a sociedade moderna como globalizada, centrada na informação e no conhecimento. Nela as pessoas e as organizações estão em um processo de contínua alteração em decorrência da revolução tecnológica das TICs, das grandes transformações sociais, políticas e econômicas. "[...] vivemos um desses raros intervalos na história. Um intervalo cuja característica é a transformação de nossa cultura material pelos mecanismos de um novo paradigma tecnológico que se organiza em torno da tecnologia da informação." (CASTELLS, 2009, p. 67)

Baseado nesse pensamento, considera-se que isso conduz à potencialização da capacidade de aprendizado e enriquecimento organizacional. Essa é uma habilidade essencial dentro da sociedade transformada pelos novos paradigmas do conhecimento e da informação. Nesse contexto, a interação entre a TI, o homem e a comunicação é essencial para proporcionar às organizações a eficiência no trato de suas atividades e a sobrevivência na Sociedade da Informação.

Assim, seguindo esta tendência, na Universidade em estudo foi implantada uma iniciativa que igualmente depende da interação desses três agentes: tecnologia, pessoas e comunicação. Essa iniciativa tem proporcionado a disseminação de parte do fluxo informacional que circula na instituição e foi denominada de Central de Informações (CEINF). Nos próximos capítulos a CEINF será mais bem explicitada, trazendo as características, objetivos e funcionamento dessa Central.

\section{PROCEDIMENTOS METODOLÓGICOS}

Quanto a sua natureza, esta pesquisa foi definida como aplicada, pois, conforme Silva e Menezes (2001), o estudo tem como objetivo gerar conhecimentos dirigidos à solução de um problema específico e envolve um interesse local.

Em busca da investigação da percepção dos sujeitos sociais envolvidos, a abordagem e objetivo do estudo foram qualitativos e descritivos, envolvendo a estratégia de estudo de caso. O estudo de caso é descrito por Yin (2005, p. 32) como "uma investigação empírica que investiga um fenômeno contemporâneo dentro de seu contexto da vida real, especialmente quando os limites entre o fenômeno e o contexto não estão claramente definidos”. Nesse sentido, a unidade de análise foi a Central de 
Informações (CEINF) de uma Universidade pública estadual do Paraná, em que foi possível buscar subsídios que respondam "como pode ser melhorada a execução das atividades de gestão informacional da CEINF”. Embora não possam ser estendidos de forma generalizada cientificamente, os resultados advindos de um estudo de caso "[...] são generalizáveis a proposições teóricas", pois beneficia-se do desenvolvimento prévio dessas proposições para "conduzir a coleta e a análise de dados". (YIN, 2005, p. 29; 33)

Quanto às fontes de evidências, a escolha foi pela observação direta nãoparticipante, entrevistas e aplicação de questionários. Envolvendo maior número de instrumentos de coleta de dados, é possível permitir maior conhecimento sobre a situação problema a fim de encontrar as respostas aos propósitos definidos. Nesse sentido, a população pesquisada na observação foi constituída pelos gestores e pelos estagiários da CEINF e por seus usuários, tanto internos como externos. Para entendimento do funcionamento da área de tecnologia e informação, foram pesquisados os gestores do Sistema de Gestão Universitária (SGU).

Segundo Pádua (2006, p. 70), as entrevistas “[...] constituem uma técnica alternativa para se coletar dados não documentados, sobre um determinado tema". $\mathrm{Na}$ entrevista livre-narrativa "Também denominada não-diretiva; o entrevistado é solicitado a falar livremente a respeito do tema pesquisado". Dessa forma, nesse tipo de entrevista não se estabelece uma ordem ou roteiro, apenas se faz uma questão inicial sobre o tema a ser investigado. No caso desta pesquisa, solicitou-se aos entrevistados que falassem sobre o histórico, estrutura, características dos atendimentos, implementações necessárias e, posteriormente, sobre as ferramentas de tecnologia e do SGU no âmbito da CEINF. Foram realizadas três entrevistas livrenarrativas com: 1) a Secretária Geral da Reitoria da Universidade, cuja função é orientar os estagiários que prestam serviço na CEINF, coordenar as atividades desenvolvidas e prover as estrutura física necessária para o funcionamento da CEINF; 2) um dos integrantes da Coordenadoria de Tecnologia a Informação da Universidade, tendo o objetivo de reunir informações acerca dos equipamentos de tecnologia instalados na CEINF e, principalmente, levantar informações sobre o funcionamento dos módulos do SGU em atividade na CEINF; 3) um dos estagiários do órgão para verificar particularidades acerca dos atendimentos. 
Além disso, foram desenvolvidos e aplicados questionários entre os usuários internos e externos da CEINF. Esses instrumentos foram aplicados entre os meses de agosto e setembro de 2011 e continham questões dicotômicas, abertas e de múltiplaescolha. Foram distribuídos 120 questionários, considerando que 50 deles foram aplicados ao público interno e 70 junto ao público externo da CEINF. Foi obtido um retorno de 44 questionários do público interno e 66 do público externo, somando 110 efetivamente respondidos.

No questionário aplicado ao público interno foi arguido, inicialmente, o grau de conhecimento das atividades da CEINF entre professores, funcionários e estagiários, ou seja, até que ponto estava difundida a existência da CEINF entre os usuários da própria Universidade. Também foram exploradas questões sobre a frequência, o grau de satisfação e os tipos de informações buscadas e divulgadas pelo público interno. Ao público externo também foram questionadas informações acerca da frequência, do grau de satisfação e dos tipos de informações buscadas pelos usuários, assim como sobre a necessidade, segundo o critério dos respondentes, de serem oferecidos outros tipos de serviços pela CEINF.

Isso exposto, confirma-se a disposição pela escolha de métodos que melhor se adequassem aos propósitos e requisitos demandados por esta pesquisa. Essa escolha procurou considerar, principalmente, a descoberta de resultados que pudessem se converter em sugestões, as quais trouxessem a melhoria das atividades de gestão informacional da CEINF, em benefício de toda a comunidade universitária.

Inicialmente, o próximo tópico trará informações sobre a Central de Informações da Universidade em estudo, apresentando suas concepções, objetivos, operacionalização, ferramentas e processos de execução. Posteriormente, serão realizadas as análises das entrevistas e questionários, seguidas das considerações finais da pesquisa.

\section{A CENTRAL DE INFORMAÇÕES DA UNIVERSIDADE NO CONTEXTO DA GESTÃO DA INFORMAÇÃO}

Para melhor explanação acerca da Central de Informações no contexto da Gestão da Informação, este capítulo foi subdividido em dois tópicos que tratam 
das concepções e objetivos da CEINF; e de sua operacionalidade por meio das ferramentas de tecnologia disponíveis e em execução na Universidade.

\section{CEINF: Concepções e Objetivos}

Idealizada em meados do ano de 2005, a Central de Informações nasceu sob a concepção de que a informação é um trunfo a serviço do indivíduo, das empresas e do cidadão. Além disso, ela faz parte de um projeto maior de ação democrática e interação social, em que incluía-se, à época, o papel da Universidade como representante e integrante de um cenário educativo que desenvolvia e se envolvia nas mais diversas atividades de ensino, pesquisa e extensão, produzindo uma gama de informações sobre cada área e atividade.

Essas afirmações constam de um Anteprojeto de Implantação do órgão, redigido em 12 de setembro de 2005. Neste documento constam, ainda, a justificativa, os pressupostos para a instalação de um Sistema de Informação na Universidade, os objetivos, os produtos, os serviços, as metas e ações e a estrutura necessária para a operacionalização da CEINF.

Salienta-se que, no primeiro momento - desde a intenção de criação do órgão -, já foi possível notar a função maior da informação como insumo para o indivíduo e para as empresas, servindo como ferramenta de interação entre esses e a comunidade (democracia e sociedade). Da mesma maneira, podem ser destacados aspectos como agilização e conveniência de serviços, tratamento e troca, valorização e organização da informação, com vistas à minimização de falhas e à tomada de decisão. Ou seja, podem ser notados princípios e pressupostos relacionados à informação que já vem sendo desenvolvidos há algum tempo e que continuam fundamentados e contemporâneos.

Desse modo, torna-se interessante ressaltar que a CEINF teve definidos seus objetivos em termos de: estudar o conteúdo próprio da informação e o seu desenvolvimento, analisando, desenhando e desenvolvendo sistemas, métodos, instrumentos e técnicas de tratamento, armazenamento, recuperação e difusão da informação; e colocar ao alcance do público as informações disponíveis.

Além dos objetivos e serviços, também foram prospectadas as metas e ações a serem alcançadas, sendo elencadas: a disponibilidade de acesso a um terminal de 
computador para os usuários inteirarem-se acerca de todas as informações disponíveis no sítio institucional; a disponibilização de mapas de serviço com a caracterização dos setores, organogramas, e demais atos administrativos; a promoção, divulgação e organização de campanhas públicas de interesse da comunidade; a composição de boletins informativos sobre dificuldades, queixas, reivindicações e sugestões encaminhadas pelos usuários, com a informação das providências tomadas; as ações com a perspectiva de fortalecimento dos direitos para a garantia da cidadania; os eventos que originassem a definição de estratégias e melhorias na qualidade dos serviços; a manutenção de um banco de dados atualizado de autoridades municipais, estaduais e federais; entre outros. Esses foram os princípios e ações que nortearam a criação e a implantação da Central de Informações da Universidade.

Passados cinco anos da sua implantação, a CEINF tem procurado atender aos objetivos inicialmente propostos, assim como prestar os serviços, gerar os produtos e atingir as metas elencadas. No entanto, naturalmente alguns desses itens foram modificados, outros substituídos e outros ainda excluídos definitivamente. Não se sabe ao certo definir o porquê das alterações sofridas por alguns itens, partindo-se de hipóteses e suposições para explicá-las. Talvez uma parcela pelo desenvolvimento natural de alguns aspectos, como por exemplo, o avanço das ferramentas tecnológicas que tornam os usuários mais independentes e autônomos. Outra pela mudança de gestão ocorrida uma ou duas vezes nesse período. Outro motivo nos leva a crer que, de acordo com uma mudança de cenário administrativo, uma mudança gerencial tenha sido necessária. Enfim, são diversos aspectos que podem ser conjecturados.

O que pode ser descrito com certeza são os procedimentos que ora se desenvolvem e sob que aspectos. Há época da pesquisa (2011) as atividades da CEINF eram realizadas por três estagiários e o atendimento aos usuários era realizado ininterruptamente das $7 \mathrm{~h} 30$ às $22 \mathrm{~h} 30$, de segunda a sexta-feira. A CEINF estava sob a supervisão direta da Secretaria Geral da Reitoria, que é vinculada ao Gabinete da Reitoria. Estava equipada com um microcomputador conectado à rede lógica da instituição, com acesso à Internet, e uma linha telefônica. Para realizar seus atendimentos, os estagiários utilizavam-se das informações de relatórios, informativos, folders e demais documentos cedidos pelos órgãos administrativos e pedagógicos, bem como tinham acesso ao sítio eletrônico da Universidade na Internet 
e ao Módulo de Trâmite de Documentos e o de Pesquisa de Ramais/Telefones Úteis, ambos do Sistema de Gestão Universitária (SGU) da instituição.

\section{Tecnologias e Sistemas de Informação: Ferramentas para Gestão da Informação da CEINF}

A gestão eficaz de todas as informações demandadas pela CEINF é uma tarefa que exige primeiramente comunicação e atualização constantes. Nesse sentido, ela necessita do maior número possível de iniciativas que proporcionem o desenvolvimento de suas atividades de forma eficaz e que gerem confiança e garantia de boa execução à comunidade universitária.

Para auxiliar na execução das atividades e no alcance das qualidades elencadas, a integração de ferramentas é indispensável. Segundo Lima Neto (2005, p. 26), “A integração dos sistemas de gestão traz modernidade e agiliza procedimentos administrativos". É nesse contexto que as ferramentas de Tecnologia de Informação (TI) e os Sistemas de Informação (SI) têm papel relevante.

No entanto, são incontáveis as vantagens de se aliar o conhecimento e o capital humano aos recursos da TI. A Universidade em estudo, percorrendo o seu caminho em busca da realização de suas atividades voltadas ao ensino, à pesquisa e à extensão, busca o aprimoramento de seus processos. Sendo assim, vem implantando diversos SIs que auxiliam as sua atividades administrativas e pedagógicas. Dentre os, aproximadamente, 22 sistemas e módulos em atividade, destaca-se o Sistema de Gestão Universitária (SGU).

O SGU é composto por módulos que geram informações e permitem gerenciar as atividades, realizando a manutenção das áreas financeira, folha de pagamento, patrimônio, gestão de pessoas, trâmite de documentos, certificados, entre outras. Todos esses módulos operam de forma individual e em constantes atualizações. Relacionado a Sistemas Integrados de Gestão e classificado como um sistema de informação Enterprise Resource Planning (ERP - Planejamento de Recursos Corporativos), o SGU teve seu primeiro módulo implantado na Universidade em 2003, com o propósito de informatizar todos os processos administrativos da instituição.

Assim, acredita-se na eficiência e agilidade que a implantação de um sistema de informações, aliado à gestão da informação e da comunicação, pode trazer à CEINF. 
Julga-se que a integração de um módulo de gestão da informação junto ao SGU da Universidade proporcionaria muitas vantagens à CEINF e também seria compatível ao que já foi elencado pelas afirmações dos autores citados neste artigo.

\section{APRESENTAÇÃO E ANÁLISE DOS RESULTADOS DA PESQUISA}

As entrevistas com os atendentes, bem como com uma das gestoras da CEINF, dão conta que eram realizados, em média, sessenta atendimentos por dia, perfazendo aproximadamente, 1.320 atendimentos mensais (em 2011). Logicamente essa quantidade diária não é estática, sofrendo variações inclusive dentro dos três períodos de funcionamento da CEINF. Há que se considerar que essa quantidade normalmente aumenta durante a realização de eventos específicos da Instituição, como congressos, seminários internacionais, nacionais, entre outros, eventos culturais, bem como em épocas de concursos docentes e de vestibulares. Naturalmente também há elevação considerável nos períodos de início de cada ano letivo.

Por meio da aplicação de dois questionários específicos para os públicos interno e externo da instituição, onde está localizada a Central de Informações, foi possível levantar os dados relacionados ao tipo de público que mais utiliza os serviços da CEINF dentro de cada categoria, que tipo de informação é mais procurada, o nível de satisfação e as sugestões e críticas apresentadas por esses públicos.

Foram distribuídos cinquenta questionários para o público interno e setenta para o externo. Desse montante, retornaram 44 questionários respondidos do público interno e 66 do público externo, somando 110 questionários efetivamente respondidos. A análise dessas informações será realizada na sequência, de forma diferenciada entre os públicos interno e externo.

\section{Apresentação e Análise dos Resultados Expostos pelo Público Interno}

O público interno é composto por professores, agentes universitários e estagiários. Procurou-se principalmente levantar junto a esse público se eles conheciam a CEINF e se dela faziam uso para resgate e distribuição de informações dentro do cenário administrativo e pedagógico da Universidade. Além disso, se a utilizassem, qual o tipo de informação mais procurada, bem como o seu nível de satisfação. Dos 44 
questionários respondidos pelo público internom, 17 respostas foram de professores, 17 de agentes universitários, 8 de estagiários e 2 de outra categoria. Vinte e sete pertencem originalmente a setores administrativos.

Sobre a questão de "conhecer" a CEINF, seis pessoas responderam que "não a conheciam", dos quais quatro são professores e dois estagiários. A análise que se faz desse fato, sobre os professores, é de que não associam a instalação da Central de Informações localizada no Hall de entrada da Universidade com o seu nome. Sobre os estagiários deduz-se que, pelo pouco tempo de atuação na Instituição, caracterizem a CEINF apenas como um "balcão" de informações, conforme descrito no questionário por um deles.

Das 44 respostas, um afirmou buscar "sempre" informações na CEINF, 15 afirmaram que buscam "às vezes", 16 "raramente" e 12 "nunca". Esse cenário demonstra que, embora a maioria busque por informações na CEINF, 27\% da amostra pesquisada não a utiliza. E dos $73 \%$ que a utilizam, apenas $2 \%$ usam "sempre". O que leva a crer que a divulgação dos serviços prestados pela CEINF deve ser incentivada.

Quanto ao tipo de informação procurada, pode-se visualizar no Gráfico 1 que $51 \%$ dos dados buscados são sobre a realização de eventos, palestras, cursos ou outras atividades (data, hora, local); $26 \%$ sobre a localização física de um setor, órgão ou departamento; $11 \%$ informações sobre uma pessoa da comunidade universitária; $6 \%$ sobre alterações na nomenclatura dos órgãos internos da universidade; e 6\% somam outros tipos de informações.

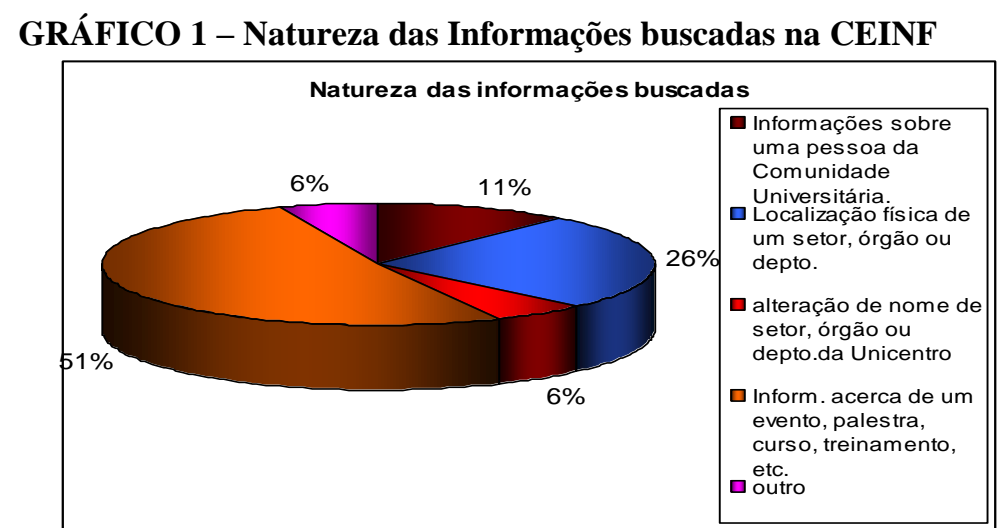

Fonte: dados da pesquisa (2011). 
Nesse aspecto, parece normal a maioria das informações buscadas serem relativas a eventos e afins, considerando que a Universidade realiza diariamente inúmeros tipos de atividades em todas as suas áreas de atuação, entre semanas acadêmicas, congressos, simpósios, seminários, cursos de extensão, entre outros. No entanto, acredita-se que o tipo de informações a ser disponibilizada ao público interno pode ser ainda mais ampliado.

Para esses tipos de informações recebidas, o nível de satisfação dos usuários internos foi classificado, em sua maioria, como "boa", 73\%; "excelente" e "regular" perfizeram um total de $12 \%$ cada; e apenas $3 \%$ foi considerada "péssima", como pode ser observado no Gráfico 2.

\section{GRÁFICO 2 - Nível de Satisfação com relação à informação recebida}

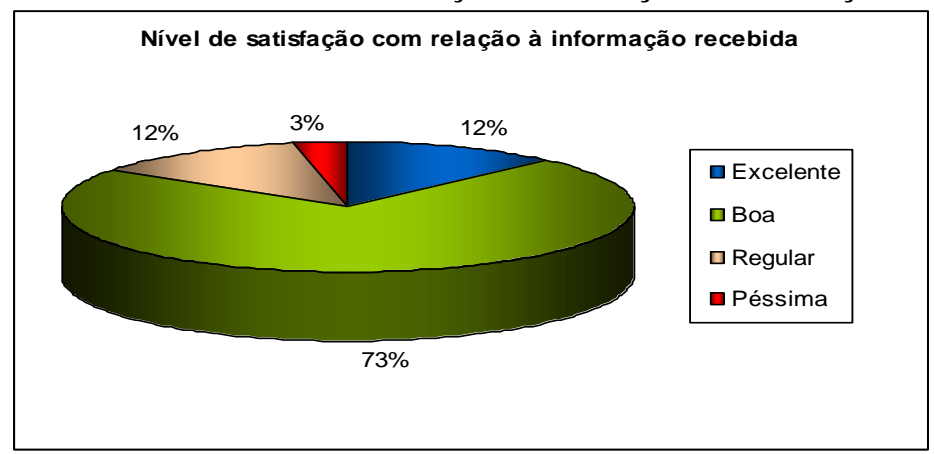

Fonte: dados da pesquisa (2011).

Considerando que o público respondente desta questão era o interno, acreditase que haja necessidade de um incremento no tipo de resposta oferecida, incluindo possivelmente informações adicionais às respostas oferecidas para os usuários. Dessa forma, o público interno poderá melhorar seu grau de satisfação em novas buscas por informações.

A segunda parte do questionário aplicado para o público interno tratou da utilização da CEINF para divulgação de informações geradas nos próprios setores, departamentos, órgãos de professores, estagiários e agentes universitários. Sobre esse tema, 66\% dos entrevistados disseram que costumam divulgar informações acerca de suas atividades internas e $34 \%$ não o fazem. Analisa-se que $34 \%$ ainda é uma margem alta de não-utilização dos serviços da CEINF, percebendo-se que também devem ser incentivadas ações que promovam a maior utilização da CEINF como órgão de divulgação da Universidade. Esse aspecto merece atenção considerando ainda que a 
frequência de divulgação é muito pequena. Apenas sete das 29 pessoas que afirmaram divulgar informações dos seus órgãos, setores, departamentos, responderam "sempre", quando perguntadas sobre a frequência de utilização dos serviços.

Acerca da natureza dos dados divulgados, a maior parte das informações divulgadas, $73 \%$, tratam sobre um evento, palestra, curso ou atividade administrativa; $16 \%$ sobre a localização física de uma instalação; e $11 \%$ outros assuntos a serem divulgados, conforme pode ser visualizado no Gráfico 3.

GRÁFICO 3 - Natureza das informações divulgadas

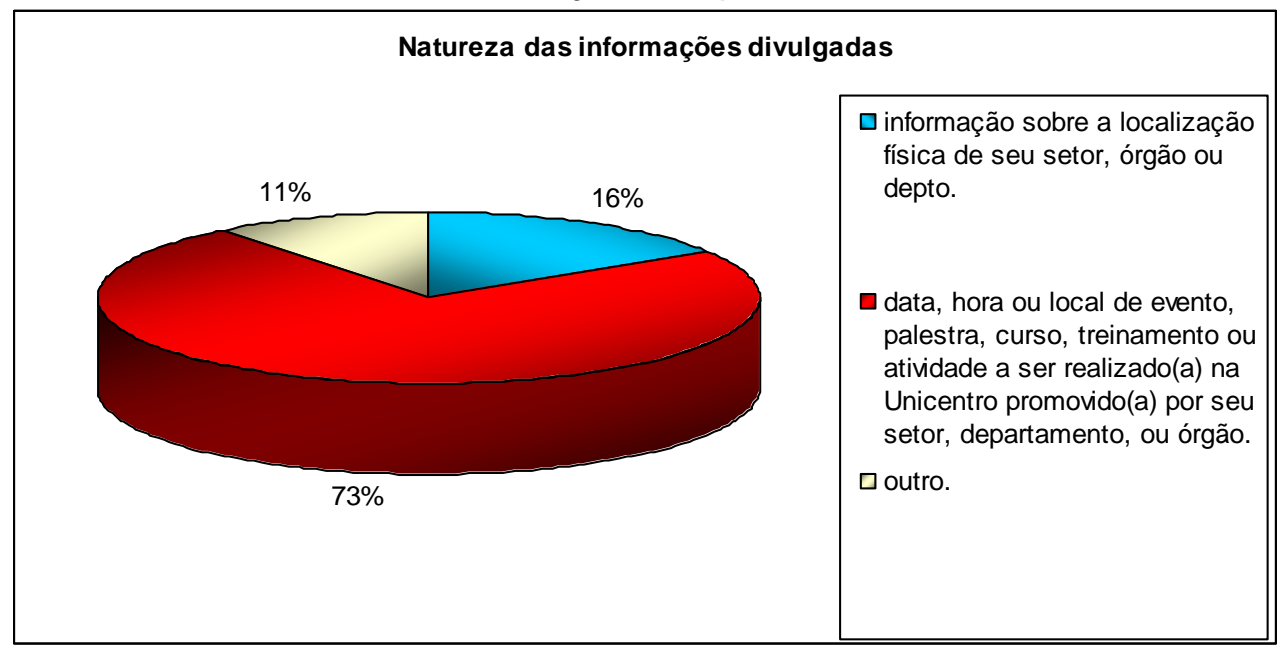

Fonte: dados da pesquisa (2011).

Nesse quesito, parece haver uma correspondência entre os itens "busca" e "divulgação" do tipo de informação. Ou seja, assim como o tipo de informação mais buscada é relativa a eventos e afins, naturalmente que o maior número de informações divulgadas será acerca do mesmo tema.

Perguntou-se também se as pessoas consultadas acreditam que a CEINF poderia oferecer outros serviços além dos já existentes. Nesse quesito, 50\% dos entrevistados acham que sim, $41 \%$ não e $9 \%$ não responderam. Chama-se a atenção para uma das respostas apresentadas: "Em princípio, deveria haver mais informações sobre a natureza dos serviços prestados pela Central de Informações. Também seria o caso de os funcionários que devem prestar informações ao público estarem mais afeitos a este atendimento". Essa resposta leva a crer a necessidade de que pessoas mais experientes nos assuntos da Universidade sejam destinadas para realização dos atendimentos na CEINF. 
Entre aqueles que sugeriram outros tipos de atividades, foram mencionados:

a) o acompanhamento das pessoas/visitantes da instituição até o local procurado;

b) na ocasião de concursos e eventos, proporcionar equipamentos com os softwares/internet que possibilitem a realização das suas inscrições direto da CEINF;

c) possuir em seu terminal o descritivo de todas as ações da Universidade que estão ocorrendo durante as semanas em curso;

d) informações ainda mais completas sobre os eventos em curso, incluindo os contatos com os coordenadores respectivos de cada um deles;

e) informações sobre o conteúdo de portarias, comissões, regulamentos, bem como dos processos licitatórios da Universidade;

f) oferecer uma relação de todas as informações que podem ser conseguidas na própria CEINF.

Analisadas as informações acerca das questões aplicadas ao público interno, no próximo tópico serão apresentadas as reflexões realizadas a partir das respostas do público externo.

\section{Apresentação e Análise dos Resultados Expostos pelo Público Externo}

O público externo está representado nesta pesquisa por 54 acadêmicos e 12 outros respondentes, entre participantes de cursos e projetos de extensão e outros. Para esse público foi questionado primeiramente sobre a frequência de busca por informações na CEINF, conforme configuração apresentada no Gráfico 4.

GRÁFICO 4 - Frequência de utilização pelo público externo

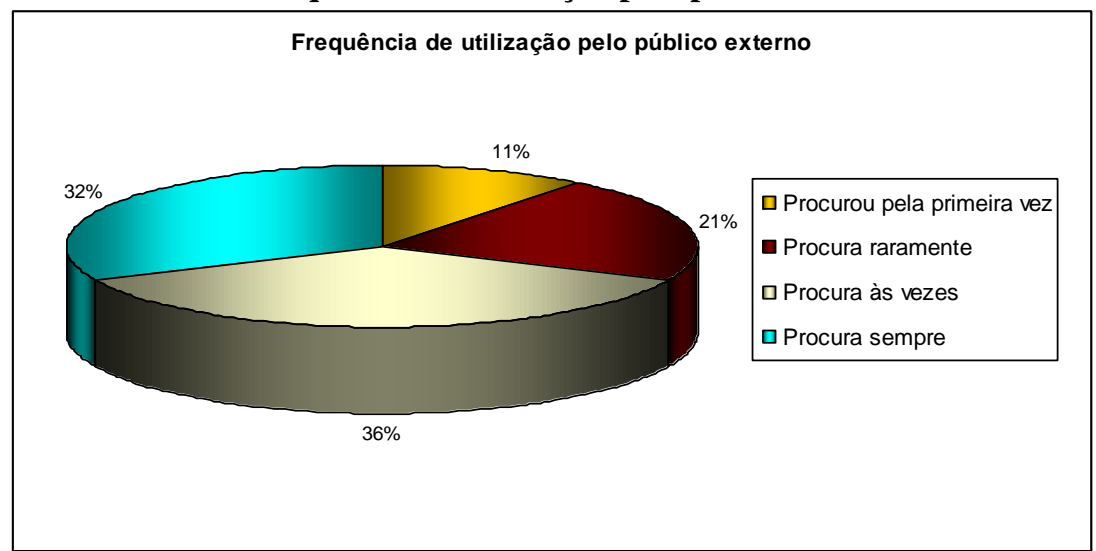

Fonte: dados da pesquisa (2011). 
Percebe-se que a procura pelo público externo é bem acentuada. Excetuandose aquelas pessoas que procuraram a CEINF pela primeira vez e as que procuram raramente, o percentual de busca é de $68 \%$. Os dados mais procurados são os relacionados a informações sobre o nome e a localização de um setor, órgão ou departamento da instituição, bem como a data, hora e local da realização de eventos, palestras, treinamentos ou demais atividades promovidas na Universidade, somando mais de $88 \%$. Essa demonstração pode ser visualizada no Gráfico 5.

\section{GRÁFICO 5 - Natureza das informações buscadas na CEINF}

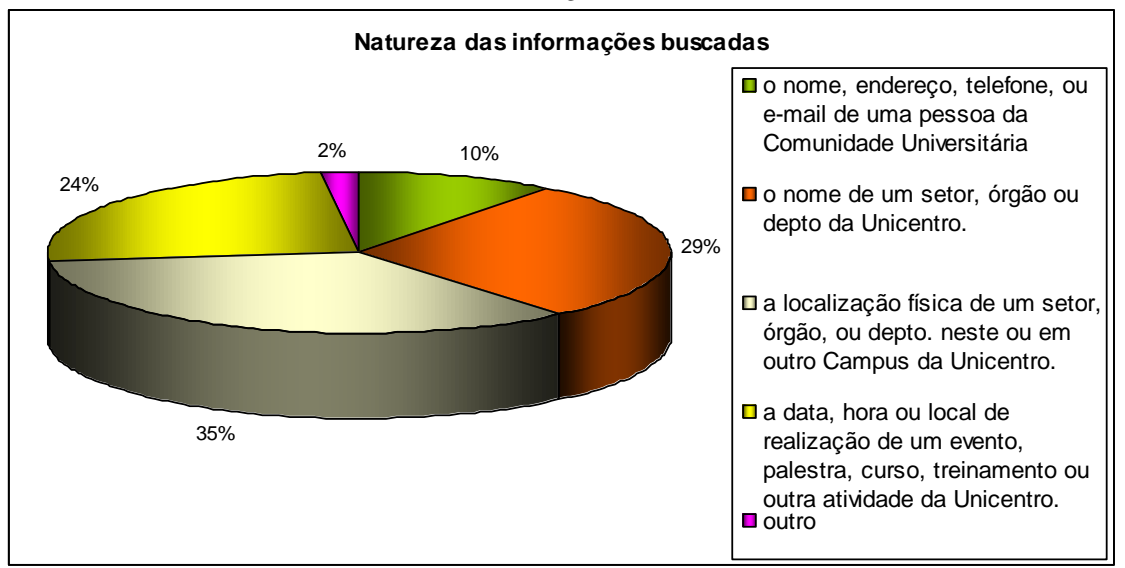

Fonte: dados da pesquisa (2011).

Analisa-se o Gráfico 5 sob duas tendências. A primeira se refere ao fato de que, imediatamente ao adentrar ao Campus da Universidade, as pessoas, visualizando a Central de Informações, encontrem naquele ponto a segurança de receber a informação correta acerca do local, nome, de um setor ou de um departamento que buscam. Portanto, é um processo natural. Quanto ao segundo aspecto, repete-se a questão já analisada no Gráfico 1. Ou seja, reflete-se aqui um dos maiores percentuais, considerando a dinamicidade de atividades em todas as áreas de atuação da Universidade, entre semanas acadêmicas, congressos, simpósios, seminários, cursos de extensão, entre outros.

O nível de satisfação dos usuários externos, quando buscaram essas informações, foi classificado em sua maioria como "excelente" $73 \%$; "boa" $23 \%$ e; "regular" e "péssimo" perfizeram um total de $2 \%$ cada, como pode ser observado no Gráfico 6. 
GRÁFICO 6 - Nível de satisfação com relação à informação recebida

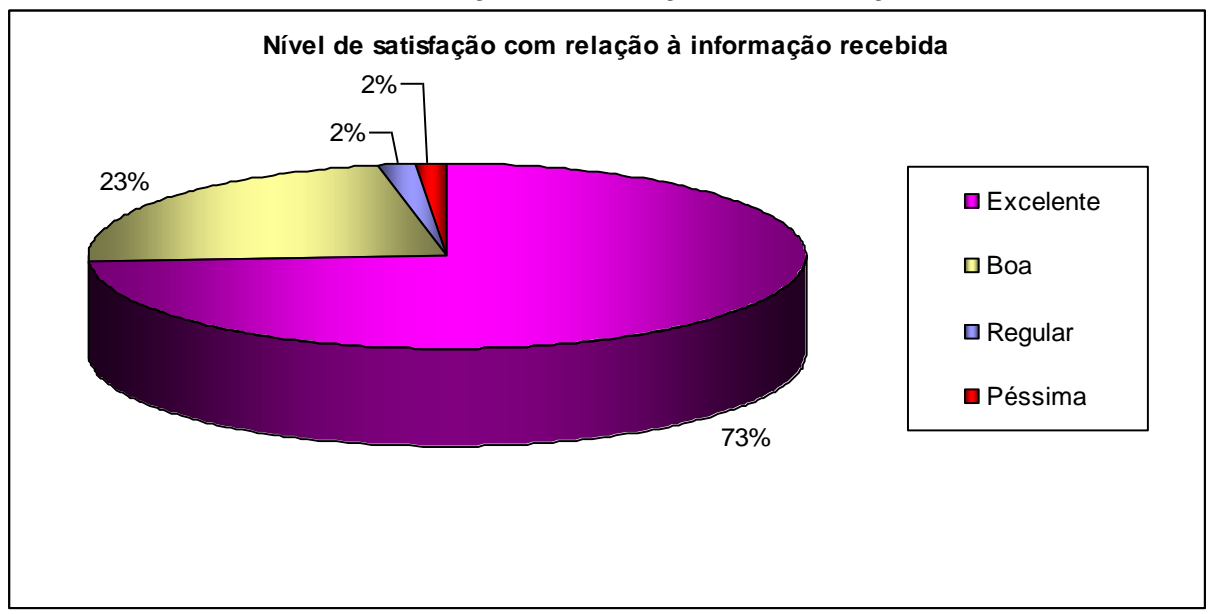

Fonte: dados da pesquisa (2011).

Esse cenário demonstra a aceitação e o grau ótimo de satisfação com relação às informações prestadas pela CEINF ao público externo da Universidade. Nesse sentido, também $79 \%$ do público externo acredita que não há necessidades de outros serviços a serem oferecidos pela CEINF. No entanto, uma pessoa sugeriu a disponibilização dos telefones dos motoristas que realizam o transporte intermunicipal dos estudantes do período noturno. Considera-se que esta sugestão foi feita devido à proximidade da Central de Informações com o acesso principal dos alunos na Instituição. Percebe-se, neste aspecto, uma visão diferente dos acadêmicos com relação a real função da CEINF.

Encerradas as análises obtidas das entrevistas e especificamente dos questionários aplicados, observa-se, de uma forma geral, que as ações da CEINF são reconhecidas pelos públicos interno e externo e atendidas de forma satisfatória. No entanto, há que se considerar que, em todas as ações, podem ser implementadas melhorias, bem como adicionadas novas ações. Essas sugestões são apresentadas no capítulo de considerações finais.

\section{CONSIDERAÇÕES FINAIS}

Este estudo teve como objetivo principal a investigação da realização da gestão informacional da Central de Informações (CEINF) de uma Universidade

\begin{tabular}{|l|l|l|l|l|l|l|}
\hline (C) Rev. digit. bibliotecon. cienc. inf. & Campinas, SP & v.11 & n.3 & p.93-119 & set./dez. 2013 & ISSN 1678-765X \\
\hline
\end{tabular}


pública do estado do Paraná, verificando-se os procedimentos executados no que se refere ao potencial informativo e comunicativo que o órgão pode oferecer. Além disso, pretendeu-se investigar como poderia ser melhorada a execução das atividades do setor, ao se apresentar como importante instrumento de gestão da massa informacional da Instituição.

Considerado o papel da CEINF e as análises feitas a partir das entrevistas, da observação e dos resultados dos questionários, acredita-se que o potencial gestor e estratégico das informações correntes da Instituição tem sido sub-aproveitado. A CEINF, ao ser criada e implantada, tinha a intenção de ser uma ferramenta de interação entre a Universidade e a sociedade, mas sobretudo previa a agilização e conveniência dos serviços com vistas à minimização de falhas e à tomada de decisão. No entanto, constatou-se, a partir dos dados levantados por esta pesquisa, que este objetivo tem sido cumprido parcialmente. A análise dos resultados demonstra que a CEINF atualmente, embora com maior potencial de trabalho, é compreendida pela comunidade universitária apenas como um "balcão de informações". Dessa forma, percebeu-se que o seu verdadeiro potencial como ferramenta estratégica e administrativa não é aproveitado em sua totalidade.

Por isso, sugere-se que a gestão superior da Universidade normalize e regulamente os procedimentos realizados pela CEINF, com vistas à melhoria da eficiência da gestão informacional da Instituição. Considera-se que a regulamentação e a normatização são necessárias para que os órgãos administrativos e pedagógicos da Universidade se habituem à existência, ao tipo de trabalho e ao potencial de otimização administrativa, estratégica e organizacional que a CEINF pode proporcionar a toda a comunidade universitária. Essas ações inclusive trariam maior divulgação dos serviços prestados pela Central de Informações perante todo o público interno da instituição, valorizando e otimizando a área de atuação do órgão entre os servidores e estagiários.

Também se justificam, a partir deste estudo, os benefícios que um módulo específico do Sistema de Gestão Universitária (SGU) para a CEINF poderá gerar em termos de capacidades informacionais. Com ele, poderia se obter maior otimização das atividades desenvolvidas nesse órgão. 
Entre outras sugestões, destaca-se também que a CEINF deveria ter uma vinculação e/ou subordinação mais efetiva com a Pró-Reitoria de Recursos Humanos da Universidade, considerando que esse é o órgão onde se originam todos os processos relacionados à gestão de pessoas. Dessa forma, a cada nova contratação/exoneração de servidores, estagiários, assessores, terceirizados e seus respectivos locais de lotação, deveria ser obrigatória e automática a atualização e comunicação dessas informações à equipe da CEINF, por meio da alimentação de módulo no SGU, bem como por meio de informativos semanais gerados pela PróReitoria. Na mesma linha de pensamento, acredita-se que também deveria haver melhor vinculação da CEINF com a Coordenadoria de Comunicação Social da Universidade. Assim, por força regulamentar e normativa, deveria existir uma sincronização de informações entre os dois órgãos, facilitando a atualização informacional relativa às atividades culturais, extensionistas e de ensino realizadas diariamente na Instituição.

Do mesmo modo, e também por força regulamentar e normativa, todos os órgãos, setores, departamentos e estruturas afins, poderiam manter um cotidiano de atualização de informações de suas atividades semanais à CEINF. No entanto, a esse procedimento poderia ser dado tratamento recíproco, ou seja, a própria equipe da CEINF buscaria, semanalmente, esses dados junto às estruturas administrativas e pedagógicas da Universidade.

Dentro desse contexto, faz-se necessária a exposição e consideração de que a lotação somente por estagiários na CEINF não é adequada, principalmente por dois importantes aspectos. Primeiro, os estagiários, por não serem servidores efetivos, não conhecem as estruturas organizacionais, administrativas e pedagógicas da Universidade em sua totalidade. Não têm a experiência e o conhecimento necessários com relação a esses aspectos, bem como a história e natureza diferenciada da instituição, detalhes os quais são mais bem dominados por servidores efetivos. $\mathrm{O}$ segundo aspecto relaciona-se ao período de permanência dos estagiários. Eles, por mais competência e empenho que dediquem às atividades, tem, impreterivelmente, seus contratos findados em, no máximo, vinte e quatro meses, necessitando, a partir disso, o recomeço dos ciclos de trabalho por outros estagiários, prejudicando o bom andamento das atividades da CEINF. 
Por meio de um servidor efetivo e com vistas a excelência profissional, sugere-se que a CEINF promova - na ocasião de novas contratações de servidores, estagiários, pessoal comissionado e/ou terceirizado - a apresentação da estrutura administrativa e pedagógica da Universidade, sua natureza institucional, bem como de seus principais regulamentos e normatizações, como por exemplo: o Estatuto, o Regimento e os regulamentos das três principais áreas de atuação da instituição (ensino, pesquisa e extensão), bem como a atribuição e regulamentos dos Colegiados Superiores da Universidade.

Reitera-se aqui que a lotação de um servidor efetivo e de experiência nos assuntos institucionais não dispensaria o trabalho de estagiários na CEINF. A permanência de um servidor efetivo à frente do órgão proporcionaria melhor controle e gestão eficaz de todas as atividades que ainda podem ser assumidas pela CEINF, considerando o seu verdadeiro potencial informacional e estratégico dentro da Universidade.

A CEINF tem plenas condições de se tornar um verdadeiro e competente órgão Central de Informações da Universidade. E, quando se diz Central, considerase que todas as informações relevantes e que gerem conhecimento institucional e administrativo, visando à otimização de todas as atividades de ensino, pesquisa e extensão, devem obrigatoriamente ser informadas e disseminadas pela CEINF.

Uma das respostas dos questionários que mais chamaram a atenção foi a de um(a) usuário(a) externo(a) que disse: "Ao responder as perguntas, constatamos a importância do setor para a instituição. Falta divulgarem as atividades que a Central pode desempenhar". Ou seja, essa resposta leva a crer que a CEINF é visualizada como órgão existente na instituição e sua intenção inicial é assimilada. No entanto, sua visibilidade pode ser melhorada por meio, inicialmente, de uma forte campanha de conscientização para que o órgão seja reconhecido e considerado como tal.

Ressalta-se, por fim, que o reconhecimento do potencial administrativo, estratégico e organizacional da CEINF depende da continuidade de seu trabalho. Mas, a essa continuidade devem ser adicionados urgentemente alguns novos procedimentos e assumidos novos papeis, sob pena de se desperdiçar o seu potencial e os recursos que ela poderia gerar indiretamente para toda a Universidade. Pois, como entidade 
pública, a Instituição deve primar pela gerência efetiva de todas as suas atividades meio e fim em busca da excelência organizacional. 


\section{REFERÊNCIAS}

AGUIAR FILHO, A. S. de. Estilos de gerência da informação, canais e ruídos de comunicação: a distribuição da informação interna na Assessoria de Comunicação na Prefeitura de Belo Horizonte. 2006. 71 f. Dissertação (Mestrado em Administração Pública) - Escola de Governo Professor Paulo Neves de Carvalho, Fundação João Pinheiro, Belo Horizonte, 2006. Disponível em: $\langle$ http://www.fjp.mg.gov.br/tede/tde busca/arquivo.php?codArquivo=58 $>$. Acesso em: 21 jul. 2010.

ALVARENGA NETO, R. C. D de. Gestão da informação e do conhecimento nas organizações: análise de casos relatados em organizações públicas e privadas. 2002. 235 f. Dissertação (Mestrado em Ciência da Informação) - Universidade Federal de Minas Gerais, Belo Horizonte, 2002. Disponível em: <http://www.bibliotecadigital.ufmg.br/dspace/bitstream/1843/VALA5G8MM7/1/mestrado_rivadavia_correia_drummond_de_alvarenga_neto.pdf $>$. Acesso em: 20 jul. 2010.

BARRETO, A. M. Gestão da informação: ferramenta da produção ou da significação? Informação \& Sociedade: Estudos, João Pessoa, v. 16, n. 2, p. 51-61, 2006. Disponível em: <http://www.ies.ufpb.br/ojs2/index.php/ies/article/view/623/1476>. Acesso em: 20 jul. 2010.

BEUREN, I. M. Gerenciamento da informação: um recurso estratégico no processo de gestão empresarial. 2.ed. São Paulo: Atlas, 2000.

BRETZKE, Miriam. Marketing de Relacionamento e competição em tempo real. São Paulo: Editora atlas, 2000

CASTELLS, M. A sociedade em rede. 6. ed. São Paulo: Paz e Terra, 2009.

CHOO, C. W. A organização do conhecimento: como as organizações usam a informação para criar significado, construir conhecimento e tomar decisões. São Paulo: Senac, 2003.

COELHO, E. A. Gestão de conteúdo na EMBRAPA. 2006. 94 f. Dissertação (Mestrado em Ciência da Informação) - Universidade Federal de Minas Gerais, Belo Horizonte, 2006.

Disponível em: <http://www.bibliotecadigital.ufmg.br/dspace/bitstream/1843/VALA6WLJUV/1/mestrado_enilda_alves_coelho.pdf>. Acesso em: 21 jul. 2010.

CORREIA, K. S. A. Metodologia para diagnóstico de problemas e fatores causadores sob o enfoque da informação - matriz PCI. 2003. 93 f. Dissertação (Mestrado em Engenharia de Produção) - Universidade Federal de Itajubá, Itajubá, 2003. Disponível em: < http://juno.unifei.edu.br/bim/0031164.pdf>. Acesso em 21 jul. 2010.

DAVENPORT, T. H. Ecologia da informação. 2.ed. São Paulo: Futura, 2000.

DAVENPORT, T. H.; MARCHAND, D. A.; DICKSON, T. (Orgs.). Dominando a gestão da informação. Porto Alegre: Bookman, 2004.

DRUCKER, P. F. O advento da nova organização. Rio de Janeiro: Harvard Business Review; Campus, 2000.

GONÇALVES, J. E. L. A tecnologia e a realização do trabalho. Revista de Administração de Empresas, São Paulo, v. 33, n. 1, p.106-121, jan./fev. 1993.

LIMA NETO, N. Prefácio I. In: SILVA, A.; RIBEIRO, J. A.; RODRIGUES, L. A. Sistemas de informação na administração pública. Rio de Janeiro: Revan, 2005.

MAIMONE, G. D. Estudo do tratamento informacional de imagens artístico-pictóricas: cenário paulista - análises e propostas. 2007. 142 f. Dissertação (Mestrado em Ciência da Informação) - Pontifícia Universidade Católica de Campinas, Campinas, 2007. Disponível em: <http://www.bibliotecadigital.puc-campinas.edu.br/tde arquivos/2/TDE-2008-02-15T144200Z1390/Publico/GIOVANA\%20DELIBERALI\%20MAIMONE.pdf >. Acesso em 21 jul. 2010.

\begin{tabular}{|l|l|l|l|l|l|l|}
\hline (C) Rev. digit. bibliotecon. cienc. inf. & Campinas, SP & v.11 & n.3 & p.93-119 & set./dez. 2013 & ISSN 1678-765X \\
\hline
\end{tabular}


MENDES, Sérgio Peixoto. Gestão do Conhecimento Individual. Florianópolis: Visual Books, 2005

MOLINA, L. G. Portais corporativos: tecnologias de informação e comunicação aplicadas à gestão da informação e do conhecimento em empresas de tecnologia da informação. 2008. 223 f. Dissertação (Mestrado em Ciência da Informação) - Faculdade de Filosofia e Ciências da Universidade Estadual de São Paulo, Marília, 2008. Disponível em: $<$ http://www.athena.biblioteca.unesp.br/exlibris/bd/bma/33004110043P4/2008/molina lg me mar. pdf>. Acesso em: 21 jul. 2010.

PÁDUA, E. M. M. de. Metodologia de pesquisa: abordagem teórico-prática. 10. ed. Campinas: Papirus, 2006.

POLLONI, E. G. F. Administrando sistema de informação. 2. ed. São Paulo: Futura, 2000.

PONJUÁN DANTE, G. Gestión de informácion: dimensiones e implementación para el êxito organizacional. Rosário: Nuevo Parhadigma, 2004.

SILVA, E. L. da.; MENEZES, E. M. Metodologia da pesquisa e elaboração de dissertação. 3. ed. rev. atual. Florianópolis: Laboratório de Ensino a Distância da UFSC, 2001. Disponível em: $\langle$ http://projetos.inf.ufsc.br/arquivos/Metodologia\%20da\%20Pesquisa\%203a\%20edicao.pdf $>$. Acesso em: 21 jul. 2010.

YIN, R. K. Estudo de caso: planejamento e métodos. 3. ed. Porto Alegre: Bookman, 2005.

\section{Como citar este artigo:}

GARDIN, Daniela do Amaral Oliveira; MAÇANEIRO, Marlete Beatriz. Central de informações em organizações públicas: ferramenta de gestão informacional. Rev. digit. bibliotecon. cienc. inf., Campinas, SP, v.11, n.3, p. 93-119, ago/nov. 2013. ISSN 1678-765X. Disponível em: <http://www.sbu.unicamp.br/seer/ojs/index.php/rbci> 